\title{
ANALISIS PERKEMBANGAN PENDIDIKAN ISLAM DI IRAN
}

\author{
Tri Yuliani, ${ }^{1}$ Iswadi, ${ }^{2}$ Desnawita, ${ }^{3}$ Armizawati, ${ }^{4}$ Desni Yulinda, ${ }^{5}$ \\ UIN Imam Bonjol Padang, ${ }^{1}$ IAIN Batusangkar, ${ }^{2.3 .45}$ \\ e-mail: triyuliani@iainbatusangkar.ac.id, ${ }^{1}$ iswadi@iainbatusangkar.ac.id, ${ }^{2}$ \\ armizawati@iainbatusangkar.ac.id, ${ }^{3}$ desnawita@iainbatusangkar.ac.id, ${ }^{4}$ \\ desniyulinda@iainbatusangkar.ac.id. ${ }^{5}$
}

\begin{abstract}
This research aims to analyze the development of Islamic education in Iran through library research or library research as a research method. Data collection in this study uses the analysis of scientific journals that have been published to see how the development process of Islamic education in Iran and see the differences in Islamic education in Indonesia. This finding produced several differences in the development of Islamic education in Iran and Indonesia. The results of this study can provide an overview of the progress of education in Iran that can be collaborated with the education system and Islamic education curriculum in Indonesia. The results of this study are expected to be useful for the public in the preparation of education curricula in Indonesia in the future.

Keywords: Development, Islamic Education, Iran, Literature Study
\end{abstract}

Abstrak

Penelitian ini bermaksud menganalisis perkembangan pendidikan Islam di Iran melalui studi pustaka atau libraray research sebagai metode penelitian. Pengumpulan data menggunakan analisis jurnal-jurnal ilmiah yang telah di publikasi untuk melihat bagaimana proses perkembangan pendidikan Islam di Iran dan melihat perbedaan perkembangan pendidikan Islam yang dilaksanakan di Indonesia. Temuan ini menghasilkan beberapa perbedaan perkembangan pendidikan Islam di Iran dan Indonesia. Hasil dari temuan ini diharapkan mampu memberikan gambaran kemajuan pendidikan di Iran yang dapat di kolaborasi dengan system pendidikan serta kurikulum pendidikan Islam di Indonesia. Penelitian ini diharapkan mampu memberikan bermanfaat untuk para pakar dalam penyusunan kurikulum pendidikan di Indonesia pada masa mendatang.

Kata Kunci: Perkembangan, Pendidikan Islam, Iran, Studi Pustaka

\section{PENDAHULUAN}

Negara di kawasan timur tengah pada umumnya merupakan Negara penyebar islam oleh Nabi Muhammad SAW diantaranya adalah wilayah Libanon, Syria, Irak, Yordania, Mesir Turki, Iran, dan kerajaan-kerajaan yang terdapat pada Teluk Persia (Iskandar, 2020). Perkembangan suatu ilmu akan mempengaruhi perkembangan suatu Negara tidak terkecuali bagi Negara islam 
88 | TAZKIR: Jurnal Penelitian Ilmu-ilmu Sosial dan Keislaman

Vol. 06 No. 1 Juni 2020

seperti Iran (Yuliani, 2018a). Pelayanan pada pendidikan tergantung pada pelayanan dan kemampuan dari negara memanfaatkan potensi sumber daya dan potensi alam yang ada di Iran(Yuliani, 2018b). Iran merupakan Negara yang memiliki relif yang tidak merata terditi dari gurung dan gurun serta punya daratan tinggi dengan luas $1.648 .180 \mathrm{~km}$ persegi yang terhampar sepanjang laut kaspia dan Uni Soviet mulai dari utara hingga ke teluk Persia yang berada di selatan dan mulai dari Turki dan Irak yang ada di Barat hingga ke Afganistan serta Pakistan Timur. Negara Iran merupakan Negara yang kaya dengan barang tambang diantaranya: minyak, gas, tembaga, dan batu bara. Ekspor minyak adalah sumber utama mendapatkan mata uang asing. Iran berpenduduk kurang lebih 65.179.752 jiwa (World Almanac 2000).

Penduduk Iran berasal dari etnis Persia, Azerbaijani dan Kurdi dengan keseharian menggunakan empat bahasa uatama yaitu bahasa Persia (resmi), bahasa Turki, bahasa Kurdi dan bahasa Luri. Pada umumnya penduduk Iran adalah muslim, di mana golongan syiah $90 \%$, dan $8 \%$ sunni. $2 \%$ lagi adalah penganut agama baha'i, mandea, hindu, zoroastrianisme, yahudi, dan kristen. zoroastrianisme, yahudi, dan kristian diakui oleh pemerintah iran, dan turut mempunyai perwakilan di parlemen. Agama baha'i tidak diakui (Donal, 1975).

Perkembangan culture masyarakat menyebabkan perbedaan antar sesama Negara meskipun berada dalam kawasan Negara islam namun memiliki ciri khas kebudayaan sendiri-sendiri yang harus dilestarikan dan dijaga terutama menyangkut Agama dan penyebarannya (Yuliani, n.d.). Dalam referensi sejarah perkembangan pendidikan Islam di Iran memberikan gambaran bahwa islam juga berkembang pesat (Tri yuliani, Armizawati, Irwandi, Desnawita, Desni Yulinda, 2020). Perkembangan Islam dalam sejaran Iran adalah pemaparan dan gambaran terkait kehidupan, aktivitas manusia di masa lalu pada periode tertentu (Rais, 2018). Mazhab syiah merupakan bukti nyata dari perkembangan sejarah Islam di Iran sekaligus sebagai bentuk mazhab yang resmi pada suatu negara (Kadir, 2016).

Iran sebagai salah satu negara tertua di di dunia, bila di telusuri secara mendalam Iran dalam catatan sejarah, hanya masa periode Safawilah di kalangan ulama Syi'ah yang mendapatkan jabatan penting dalam suatu pemerintahan dikarenakan kalangan ini berhasil menyatakan dirinya sebagai keturunan langsung dari Imam (Sudrajat, 1996). 
Penyebaran Islam di Iran dimulai dengan rentang yang sangat panjang dalam beberapa masa dan periode yang terjadi seiring dengan pergantian kekuasaan kerajaan. Kronologis berdirinya Republik Iran diantaranya:

\section{Dinasti Ikhaniyah (tahun 1256-1336)}

2. Perpecahan menjadi rezim lokal

3. Penaklukkan Timur

4. Negara setelah Timuriah

5. Rezim safawiah

\section{Rezim Safawiah}

\section{Rezim Afshariah}

Peradaban tertua di dunia dicatat dalam sejarah ditempatkan pada negara Iran yang memiliki usia sekitar 2700 SM (John, 1995). Iran menjadi negara islam tertua pada tahun 1979 (Lapidus, 2003). sejarah menyatakan hal ini dimulai dari kemenangan oposisi Ayatullah Khomeini ${ }^{1}$ sebagai tokoh revolusioner dan tokoh syiah. Berbicara terkait sejarah Islam dan perkembangan Islam pada negara Iran tidak terlepas dari sejarah peradaban kaum Syiah. berdasarkan uraian diatas juga di pahami bahwa Iran juga tidak terlepas dari perkembangan kerajaan pada masa Safawi, dimana kerajaan masa ini menganut mazhab Syiah. secara kesimpulan utama menyatakan bahwa perkembangan islam di Iran merupakan perkembangan pada mazhab Syiah di Iran.

Berdasarkan rangkaian pembahasan diatas, Perkembangan Islam di Iran menjadi Kajian yang sangat menarik untuk dikaji dan dipelajari untuk menambah khasanah pengetahuan yang lebih dalam hingga kedepannya dapat menjadi rujukan masa dari perkembangan islam di dunia tidak terkecuali di Indoensia. pada dasarnya perjalanan sejarah Islam pada negara Iran menjadi

1 Ayatullah Khomeini (1992-1989) merupakan satu-satunya tokoh yang sering disebut, saat dikaji dalam kajian sejarah islam terutama memasukin periode revolusi negara tersebut. Khomeini lahir pada desa di khomain dekat Teheran. Khomaini memperoleh pendidikan pertamanya di Khomani dan Arak, lalu berhijrah ke Qum untuk menuntut ilmu yang lebih tinggi. Ringkasan lebih panjang tentang riwayat Khomaini dapat di baca pada Nuruzzaman Siddiqie, Syiah dan Thawarij dalam Perspectif Sejarah (Yogyakarta: PLP2M, 1985),34-37. 
90 | TAZKIR: Jurnal Penelitian Ilmu-ilmu Sosial dan Keislaman

Vol. 06 No. 1 Juni 2020

peristiwa penting sejarah perkembangan islam yang penting untuk ditelusuri demi memberikan gambaran pengetahuan pendidikan islam dimasa mendatang.

\section{LANDASAN TEORI}

\section{Sekilas Tentang Iran}

Peradaban Iran bermula dari ratusan tahun sebelum masehi. Iran memiliki keberagaman dalam warisan negaranya dengan arsitektur dan pola kebudayaan yang tampak sejah abab ke-6 masehi. Iran memiliki kekaisaran tertua yang kaya dengan Ilmu pengetahuan. pemerintahan di iran pada masa kekaisaran dipegang teguh oleh sistem kebijakan nasional social dan politik. Pada masa kerajaan dan berbagai dinasti menyebabkan Iran mempunyai cita-cita yang mulia dengan memodernisasi Iran namun cita-cita tersebut membuat gejolak pada masyarakat yang menyebabkan banyak pertentangan di negara Iran. pada masa kejaraan Khomaini, Iran berubah menjadi negara Islam yang berganti nama lengkap menjadi Republik Islam Iran (jumhurî islamî îrân) (Badri, 2003).

Iran adalah salah satu di antara anggota pendiri Perserikatan Bangsabangsa (PBB), Organisasi Konferensi Islam (OKI), dan Gerakan Non-Blok. Sistem politik di Iran berasaskan konstitusi yang dinamakan "Qanun-e Asasi" (Undangundang Dasar). Terdapat berbagai lembaga penting di Iran di antaranya pemimpin agung. Pemimpin Agung Iran bertanggung jawab terhadap "kebijakankebijakan umum Republik Islam Iran"(Ensiklopedi, 1994). Tanggung jawab presiden adalah memastikan konstitusi Negara diikuti dan juga mempraktikkan kekuasaan eksekutif. Tetapi presiden tidak berkuasa atas perkara-perkara yang di bawah kekuasaan pemimpin agung. Presiden melantik dan mengepalai Kabinet Iran serta berkuasa membuat keputusan mengenai administrasi negara (Ensiklopedi, 1994).

\section{Perkembangan Sistem Pendidikan Islam pada negara Iran}

Nama Republik Islam Iran berawal dari sebutan Persia yang mana pada masa itu setelah revolusi yang terjadi di Iran. Iran pada masa itu dikenal sebagai Negara yang berada pada kawasan Timur Tengah di Asia Barat daya. Perkembangan pendidikan pada masa itu dilakukan secara bertahap yang menjadi focus penting dan pertama dilakukan oleh Negara Iran. Sistem yang dilakukan Iran pada utamanya mengirimkan mahasiswa ke luar negeri untuk belajar dalam bidang militer namun pada saat itu juga misi Iran mendatangkan Instruktur dari Negara Eropa untuk memberikan ilmu dan mengajarkan para militer yang ada di 
Iran setelah mengalami kegagalan dan kekalahan dalam perang mengusir penjajah dari Rusia (Shahvar, 2009).

Hingga masa saat ini pemuda yang menjadi mahasiswa asal Iran terus belajar dan menambah pengetahuan ilmu ke luar negaranya dengan berbagai macam cara dan alas an demi kemajuan Negara pada masa mendatang. Berdasarkan hasil pencatatan awal pada tahun 2010 Negara Iran mengirimkan 38.125 orang mahasiswa ke luar negeri untuk memperoleh penddikan yang layak, data yang di publish oleh Unesco Institue For Statistic (UIS) sedangkan 2 tahun sebelumnya haya berjumlah 26.928 mahasiswa. Jumlah pada tahun yang sama, Negara pendatang mencatat ada sekitar 26.647 mahasiswa internasional yang menempuh pendidikan tinggi ke luar negeri. Dari data menggambarkan bahwa iran terus mengalami peningkatan dalam bidang pendidikan yang dibuktikan banyaknya peminat yang meneruskan pendidikan ke luar negeri.

Peminat yang banyak akan secara tidak langsung menyatakan bahwa Iran memiliki kualitas pendidikan yang tinggi dan daya saing dalam pendidikan yang cukup bagus di ruang lingkup Internasional.

\section{Tujuan Pendidikan}

Pemerintah Iran menunjuk suatu lembaga yang akan mengelola proses ketercapaian pendidikan melalui lembaga Kementerian pendidikan negara Republik Islam Iran yang secara keseluruhan menegaskan tujuan umum pendidikan pada Negara Iran sebagai berikut:

1. Kriteria dalam pengembangan fisik. siswa diwajibkan untuk mempelajari beberapa pengetahuan terkait kesehatan dan melakukan praktek olah raga untuk kebugaran dan keterbukaan pola piker siswa.

2. Kriteria pengembangan ilmu social. Siswa diajarkan cara menghormati dan menghargai orang tua, keluarga, masyarakat dan diri mereka sendiri yang berkaitan dengan kebabasan pribadi. Siswa dituntut untuk memahami kehidupan bersosial, ekonomi dan bertahan hidup dalam kondisi dan situasi lingkungan yang tidak mencukung sera berusaha hisup dan mengabdi untuk masyarakat disekitar.

3. Kriteria dalam mencapai tujuan pengembangan intelektual dan intelegensi siswa. Siswa diwajibkan untuk belajar mengasah pola pikir dan belajar dari pengalaman yang diperoleh mereka dari sesama masyarakat dan lingkungan. 
92 | TAZKIR: Jurnal Penelitian Ilmu-ilmu Sosial dan Keislaman

Vol. 06 No. 1 Juni 2020

4. Kriteria dalam pengembangan Moral, sikap siswa. Siswa diwajibkan untuk memahami agama, peradaban sehingga melalui hal itu siswa mampu mengendalikan dan menjaga diri sendiri.

5. Kriteria dalam pengembangan estetika. Siswa wajib menanamkan cinta alam dan memperkuat kepribadiannya melalui kenikmatan ilmu seni.

Usaha dalam pencapaian pendidikan berdasarkan kriteria tujuan yang ditetapkan dilakukan dengan mengarahkan pada ajaran dan penggunaan Alguran, kebiasaan dan tradisi islam yang berlaku pada Negara Republik Islam Iran. Berdasarkan hal tersebut dirumuskan beberapa tujuan dan capaian sasaran pendidikan Republik Islam Iran sebagai berikut:

1. sirah nabawiyyah, khulafa' ar-Rasyidin dan tokoh-tokoh Islam menjadai bahan acuan dalam memamahi nilai kehidupan.

2. Bersikap dengan mengamalkan nilai-nilasi sikap yang terpuji dan beperilaku akhlak yang mulia.

3. Pada pelajaran dan pembelajaran yang dilakukan pada pendidikan islam dengan memperhatikan tata cara menulis dan membaca (Fikri, 2019).

\section{Struktur dan Jenis Pendidikan}

Sistem pendidikan Republik Islam Iran mengalami perubahan dan bersifar terpusat/ sentralistik yang diuraikan dalam bentuk pendidikan tingkat sekolah dasar, tingkat sekolah menengah dan tinggat pendidikan tinggi. Pendidikan pada tingkat sekolah dasar dan tingkat sekolah menengah dibawah pengaturan dan nauangan dari Lembaga Departemen Pendidikan (Ministry of Education) dan untuk pendidikan tinggi berada di bawah pengawasan dan pengaturan dari Departemen system dan proses dari prosedur pendidikan tinggi. System dan pengelolaan pendidikan Iran secara lebih terarah akan digambarkan pada jabaran dibawah ini:

\section{Pendidikan sebelum sekolah (Prasekolah)}

Pendidikanmasa ini pendidikan dilakukan oleh lembaga-lemabaga swasta yang memberikan pengenalan dalam ilmu pendidikan dan mempersiapkan anak-anak dibawah usia sekolah untuk melanjutkan pada pendidikan fotmal nantinya. Pengajaran yang dilakukan pada pendidikann tingkat prasekolah ini sangat sederhana yang dimulai dengan pengenalan angka huruf dan merangkai kata. Memberikan tugas dan pelajaran yang dilaksanakan dengan bernyanyi bermain, menari dan berhitung. Proses 
pembelajaran dengan langkaj yang sederhana dengan melukis, membacakan cerita/ mendongeng dan melakukan pekerjaan tangan yang sangat simple dan mudah. Sarana dan prasarana dengan menggunakan papatulis, pena, dan kertas biasa untuk belajar.

\section{Pendidikan Awal (Dasar)}

Pelaksanaan pendidikan ini dilakukan pada anak-anak berusia lebih kurang 6 tahun dengan masa ajar dab belajar disekolah selama 6 tahun secara berkesinambungan yang diikuti dengan masa orientasi dan pengenalan pada anak terkait pendidikan dan pelajaran selama 3 tahun.

Pengenalan pada masa orientasi bagi anak bertujuan utnuk memberikan pengaruh dan stimulasi bagi pada peserta didik/siswa untuk menyambung dan melanjutkan sekolah mereka pada jenjang tingkat pendidikan yang lebih tinggi di masa mendatang dapat digunakan untuk mencari pekerjaan.

\section{Pendidikan lanjutan (Menengah)}

Kriteria pendidikan selanjutnya adalah pendidikan menengah yang dilaksanakan kurun waktu 4 tahun dimana proses masa ini dibagi menjadi 2 jalur pendidikan yaitu jalur akademik yang berkaitan denganbidang sanins dan humaniora, dan jalur kedua berkaitan dengan teknik dan kejujuran sikap. Disisi lain jalur yang berhubungan dengan bidang insdustri dan pertanian belum berkembang dengan pesat atau kurang peminat melihat kondisi dan culture budaya yang ada di Republik Islam Iran.

Proses pendidikan masa menengah memberikan pengarahan dan pembinaan setelah lulus dan sebelum memulai tingkat pendidikan pada jenjang pendidikan yang lebih tinggi atau Universitas bagi siswa selama 1 tahun. Setelah menempuh pendidikan tersebut dan lulus maka siswa dapat melajutkan pendidikan dengan tahapan sebagai berikut: 1) Teknik/vocational school (Fogh-e-Diplom atau Kardani) lama pendidikan dua tahun. 2) Univesitas/bachelor degree (Karsenase atau licence) lama pendidikan empat tahun. 3) Master degree (karsenase-ye Arsyad atau Fogh Lisence) lama pendidikan dua tahun. 4) Program doktor/PhD (Karsenasi Arshad - napayvasteh atau Doktora) lama pendidikan tiga tahun.

\section{Pendidikan Tinggi}

Pada masa pendidikan sekolah tinggi ada dua lembaga Kementerian yang bertanggung jawab untuk pendidikan pasca-sekolah menengah adalah Departemen Kebudayaan dan Pendidikan Tinggi (MCHE) dan Departemen 
94 | TAZKIR: Jurnal Penelitian Ilmu-ilmu Sosial dan Keislaman

Vol. 06 No. 1 Juni 2020

Kesehatan dan Pendidikan Kedokteran (MHME). Pendidikan tinggi terbagi dalam sekolah tinggi pendidikan guru yang tidak menuntut tamatan pendidikan menengah sebagai persyaratan masuk dan berbagai sekolah tinggi lain dan universitas. Tetapi banyak mahasiswa yang belajar di luar negeri.

\section{METODE PENELITIAN}

Penelitian ini merupakan penelitian dengan kajian pustaka menggunakan metode penelitian yang bersifat studi kepustakaan yang melihat masalahmasalah yang diteliti dan mencari sumber informasi berdasarkan literature, teori dan artikel yang dipublikasikan dalam berbagai jurnal ilmiah.

\section{HASIL DAN PEMBAHASAN}

\section{Kebijakan Pemerintah dalam Pengelolaan Pendidikan Islam di Iran}

a. Tujuan Pendidikan dan Kebiijakan pemerintah.

Tujuan pendidikan suatu Negara akan selalu mengalami perubahan yang berhubungan dengan perkembangan dan kemampuan Negara dalam mengalami trnaspormasi dalam dunia pendidikan itu sendiri. Seingi perubahan Negara juga berkaitan dengan system dan perundang-undang yang mengatur pendidikan di suatu Negara.

b. Sistem pelaksanaaan kurikulum pendidikan Islam di Iran

Lembaga pendidikan islam di Iran memiliki struktur pendidikan khusus dan memiliki tingkatan pendidikan tersendiri yang terdiri atas:

1) Tingkat pertama adalah sekolah dagang pasca SD (sekolah dasar) yang terkait dengan sekolah menengah pertama. Ini merupakan program akhir yang diarahkan pada pelatihan siswa agar mejadi pekerja yang mahir dan terampil.

2) Tingkat kedua, berkaitan dengan sekolah menegah atas denga tujuan melatihh para ahli teknik dan industry.

3) Tingkat ketiga yaitu sekolah tinggi teknik yang menerima siswa yang telah lulus atau menyelesaikan program akademik sekolah menengah atas atau sekolah teknik. Sekolah tinggi ini dimaksudkan untuk melatih para insinyur dan teknisi (Assegaf, 2003).

Selain lembaga pendidikan formal, di Iran juga terdapat lembaga pendidikan non formal seperti maktab dan masjid yang memberikan 
pelajaran tentang Alquran, logika, bahasa Arab, dan gramatika (nahwu). Suatu yang juga penting diketahui adalah setelah pasca revolusi, Iran menjalankan kegiatan pendidikan non formal dalam bentuk pemberantasan buta huruf (illiteracy) dengan cara bekerja sama dengan UNESCO dan UNDP yang dinamakan dengan "The World Experimental Literacy Programme" dengan pusat kegiatan di Esfahan di Iran tengah dan Dezful di selatan. Kemudian kegiatan pendidikan ini ditambah dengan kegiatan pelatihan keterampilan atau latihan kejuruan seperti montir mobil dan petani gula. Program ini mampu menekan akan buta huruf cukup tinggi yang menjangkau 3 juta rakyat dengan 167.000 kelas (Assegaf, 2002). Kota Qum sebagai kota atau pusat pendidikan telah dibangun sejak awal oleh Imam Khameini (Hamzah, 2017)

Pelaksanaan pendidikan islam di Iran merujuk pada penetapan kurikulum pendidikan Islam di Iran yang masih terpusat pada sistem pemerintahan yang terfokus. Dalam hal ini menggambarkan bahwa pendidikan Islam sepenuhnya di kelola oleh pemerintah dengan menentukan dan menetapkan pola pendidikan di negarasnya. Berbeda dengan perguruan tinggi, dosen memegang peranan penting dalam menentukan isi mata kuliahnya (Nur, 2017). Pola kurikulum di lembaga pendidikan Islam Iran adalah kumpulan integrasi rumpun ilmu pengetahuan kemanusiaan (soft scinces) dan rumpun ilmu pengetahuan alam (hard scinces).

\section{Perbedaan dan Perbandingan Pendidikan antara Iran dan Indonesia}

Jenjang pendidikan formal iran secara sederhana adalah : 1) Pendidikan Prasekolah; 2) Pendidikan Dasar; 3) Pendidikan Menengah; 4)Pendidikan Tinggi. Jenjang Pendidikan di Indonesia Berdasarkan Undang-undang Pendidikan Nasional tahun 2003. Jalur, jenjang dan jenis pendidikan dapat diwujudkan dalam bentuk satuan pendidikan yang diselenggarakan oleh Pemerintah, Pemerintah Daerah, dan/atau masyarakat. Adapun jenjang pendidikan tersebut antara lain:

1. Iran memiliki kembaga penyelenggaraan pendidikan dibawah naungan kementrian pendidikan sedangkan Indonesia berada dibawah naungan Kementrian agama yang memasukkan kurikulum keislaman dalam bidang pendidikan 
96 | TAZKIR: Jurnal Penelitian Ilmu-ilmu Sosial dan Keislaman

Vol. 06 No. 1 Juni 2020

2. Iran memiliki jenjang pendidikan formal yang pada umumnya sama dengan Indonesia dengan sebutan nama berbeda. Iran: Pendidikan Prasekolah dan Indonesia: Pendidikan Anak Usia Dini (PAUD)

3. Biaya pendidikan pada iran dilaksanakan dengan non biaya alias gratis dari pendidikan dasar hingga menengah sedangkan Indonesia membebankan sepenuhnya biaya pendidikan pada pemerintah.

4. Kesejahteraan guru sangat diperhitungkan pada negara Iran dengan pembayaran perbulan sebanyak US300 sedangkan Indonesia diatur dalam Undang-undang dan berdasarkan golongan

5. Anggaran pendidikan pada Iran dianggarkan sebanyak $40 \%$ sedangkan Indonesia menganggarkan sebanyak $20 \%$ dari dana APBN

\section{KESIMPULAN}

Iran sebagai Negara yang unik dengan bentuk pemerintahan republik Islam. disamping sebagai Negara republic yang kepala negaranya dipegang oleh presiden, ternyata Iran memiliki jabatan tertinggi di atas presiden yang bertugas sebagai pengawas dan penentu kekuasaan tertinggi di Iran yaitu wilatul faqih, dengan aliran mazhabnya adalah syi'ah Itsna asyari. Perkembangan Iran pada masa revolusi telah mengubah semua sistem pada negara Iran tiak terkecuai pada sistem pendidikan yang harus disesuaikan pada prinsip pelaksanaan di negara Iran. Prioritas pendidikan negara Iran tertelatak pada tahap jenjang pendidikan yang dilaksanakan muai dati lembaga sekolah dasar hingga sekolah pendidikan tinggi. Iran memfokuskan pendidikan dengan mengirim dan mendukung masiswa negaranya untuk menambah ilmu pengetahuan ke luar negaranya serta mengratiskan biaya pendidikan di negaranya sendiri hingga pendidikan tinggi.

Iran sebagai negara yang banyak penghasil tambang memberikan $40 \%$ dana APBN pada pelaksanaan pendidikan. Iran termasuk negara yang mensuport penuh pendududknya dalam bidang pendididkan. Pendidikan swasta juga dilaksanakan di Iran dengan ketentuan boleh memungut biaya pendidikan dari sekolah tersebut. Iran termasuk negara yang konsisten terhadap pendidikan di Negaranya. 


\section{Rujukan dari buku}

\section{DAFTAR PUSTAKA}

Abd. Rahman Assegaf. (2003). Internasionalisasi Pendidikan Islam; Sketsa Perbandingan Pendidikan di Negara-negara Islam dan Barat, Yogyakarta: Gama Media. 83-84

Donald, W, (1975). Iran; Past \& Present, New Hersey: Princeton University Press, 161-163.

Hairulfikri. 2019. Kurikulum Pendidikan Islamhttp://hairulfitriislamicbook.blogspot.co.id/2010/03/kurikulum-pendidikan-islam-dimalaysia.html, diakses pada tanggal 10 September 2019. h. 3.

Hamzah Harun al-Rasyid, googleweblight.com/?lite_url=http://hamzahharun.blog. diunduh pada tanggal 06 Januari 2017.

Heriyanto, H. (2012). Islam, Iran dan Peradaban; Peran dan Kontibusi Intelektual Iran terhadap Peradaban Islam. Yogyakarta: Rausyan Fikr Institut.

Iskandar. (2020). Perkembangan Dakwah Islam di Iran. Pare: STAIN Pare

John E., Jessup, (1989). A Chronology of Conflict and Resolution, 1945-1985. New York: Greenwood Press

K. Hitty, P. (2010). History Of Arabs. Jakarta: PT Serambi Ilmu Semesta.

Kadir. A. (2015). Syiah dan Politik: Studi Republik Islam Iran. Jurnal Politik Profetik, 5 (1). 1-15.

M Lapidus, Ira, (1999). Sejarah Sosial Umat Islam (Bagian ketiga), Jakarta: Rajawali Pers.

,(1999). A History of Islamic Societies, (Bagian1 dan 2), Jakarta: PT.Radja Grafindo Persada,

Mun'im Al Nimr, Abdul. (2003). Imam Mahdi dan Duruz; Sejarah dan Fakta, Penerjemah Ali Mustafa Ya'qub, Jakarta: Qisthi Press.

Muthahhari, M. (2012). Islam, Iran dan Peradaban; Peran dan Kontribusi Intelektual Iran terhadap Peradaban Islam. Yogyakarta: Rausyan Fikr Institut.

Rahman A. (2003). Internasionalisasi Pendidikan Islam; Sketsa Perbandingan Pendidikan di Negara-negara Islam dan Barat, Yogyakarta: Gama Media,

Rais, M. (2018). Sejarah Perkembangan Islam di Iran. Tasmuh: Jurnal Studi Islam, $10(2), 273-288$. 
98 | TAZKIR: Jurnal Penelitian Ilmu-ilmu Sosial dan Keislaman

Vol. 06 No. 1 Juni 2020

Szyliowics, Josep. (2001). Education and Modernization in Middle East, Alih bahasa Ahmad Djainuri, Surabaya: al-Ikhlas.

Shabani, R. (2005). The Book of Iran; Iranian History at A Glance, Tehran: Alhoda International Publiser.

Soli, S. 2009. The Forgotten Schools; The Baha'is and Modern Education in Iran, 1899-1934, London and New York: I.B. Tauris Publishers.

Sudrajat, A. (1996). Imam Al-Khumaini dan Negara Republik Islam Iran. Cakrawala Pendidikan, 1 (15). 35-46.

Syah N, Agustiar, (2002). Perbandingan Sistem Pendidikan 15 Negara, Bandung: Lubuk Agung,

Thohir, A. (2011). Studi Kawasan Islam; Perspekti Etno-Linguistik dan GeoPolitik, Jakarta: Rajawi Pers.

UNESCO Institue for Static. 2010. Global Education Digest Comparing Education Statistics Across The World. Canada: UNESCO Institute for Statistics.

Yuliani, T. (2018a). Pengembangan E-Library dalam Meningkatkan Pelayanan di Perpustakaan IAIN Batusangkar. Alfuad: Jurnal Sosial Keagamaan, 1(1), 16.

Yuliani, T. (2018b). The influence of the quality of service to customer loyalty. AlFuad 2018, 2(1), 35-47.

Yuliani, T. (2020a). Pemberdayaan Masyarakat Desa melalui Pemanfaatan Koleksi pada Perpustakaan Darul Hikmah Mesjid Nurul Falah. At Taghyir, (2)2, 219-232.

Yuliani, T. (2020b). Analisis kebutuhan pemustaka pada kegiatan layanan pengembangan koleksi buku Perpustakaan IAIN Batusangkar. Al Kutab: Jurnal Kajian Perpustakaan, Informasi dan Kearsipan, 2 (1), 41-52.

\section{Rujukan dari Internet}

Al-Rasyid, Hamzah Harun, googleweblight.com/?lite_url=http://hamzahharun.blog. diunduh pada tanggal 06 Januari 2017

Rasidin,googleweblight.com/

lite_liteurl=http://ejournal.Iainjambi.ac.id/index.php/media akademika/ diakses tanggal 20 Oktober 2016 